\title{
Hydroxychloroquine - How Much Is Too Much?
}

Although initially approved for medical use in the United States by the Food and Drug Administration in the 1950s, antimalarial treatment of clinical disease actually dates back to the 1630s in Peru, stemming from the "fever tree," later identified as Cinchona officialis in 1742 by Carl Linnaeus in Europe $^{1}$. Later, quinine was isolated from Cinchona bark ${ }^{2}$, yielding the subsequent boom in the development of these agents for the antimalarial market. When the Dutch Cinchona plantations were overrun and captured during World War II, a synthetic version of quinine was created - quinacrine and was used for malaria prevention, an activity funded and supported by the war effort in the United States ${ }^{3,4}$. The quinacrine story bears an uncanny similarity to the development of synthetic corticosteroids, which was also supported by the needs of the US government for the war effort during the exact same time period. It was in 1951, after the war was over, that Allied soldiers taking longterm quinacrine demonstrated improved signs and symptoms of systemic lupus erythematosus (SLE) ${ }^{5}$. Just a few years later (1955), hydroxychloroquine (HCQ) was synthesized, and a successful scale-up created this cornerstone drug for treating SLE. It is now on the World Health Organization list of essential medications needed in a basic health system ${ }^{6}$.

In this issue of The Journal, Tselios, et $a l^{6 a}$, report from their cohort the diagnosis, disease course, and outcome of 8 patients with antimalarial-induced cardiomyopathy, an underrecognized complication that has been reported with longterm use and higher cumulative doses of chloroquine and $\mathrm{HCQ}^{7}$. To better understand the risks posed by this case series, we must first review the biological pharmacology and pharmacodynamics of HCQ.

HCQ is a 4-aminoquinolone with an elimination half-life of 40-50 days and a volume of distribution of $50 \mathrm{l} / \mathrm{kg}^{8}$, which allows for sustained sequestration in the tissues and sometimes leads to irreversible organ damage. It differs from chloroquine by a single hydroxyl group, and is composed of both hydrophilic and hydrophobic regions. The hydrophilic region allows HCQ to be rapidly absorbed from the gut and
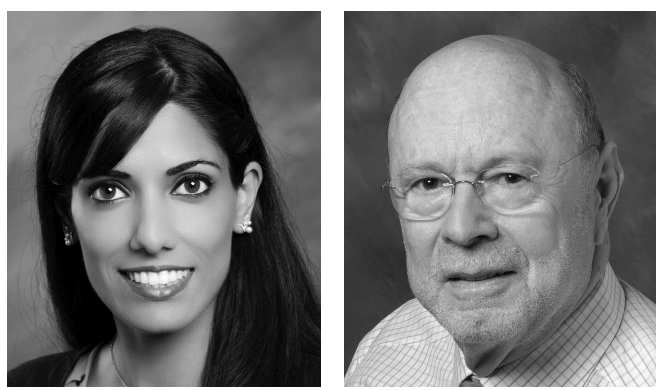

metabolized by CYP450 in the liver to N-desethylhydroxychloroquine, a weak base that accumulates in acidic vesicles (endosomes, lysosomes), resulting in an increase in the $\mathrm{pH}$ of these cellular compartments. Although the exact therapeutic mechanism of action of this drug in patients with SLE is still a subject of debate, modern tools in the laboratory have narrowed the focus. Its presence in vivo inhibits the activation of intracellular Toll-like receptor signaling, antigen processing, and presentation through the MHC class II pathway, and subsequently modulates the production of proinflammatory and antiinflammatory cytokines $8,9,10$. However, the toxicity or off-target effects of this agent have never been adequately characterized, perhaps largely owing to the rather commonly accepted safety profile of the drug. Nevertheless, the hydrophobic region plays a role in partition of the molecule into membranes that interact with membrane phospholipids and neutralize phosphate charges, which displaces calcium and results in a process that may also cause muscle necrosis ${ }^{10}$.

While generally well-tolerated systemically, the side effect profile of HCQ is typically mild and ranges from rash (rarely severe) to central nervous system symptoms (principally headaches) or diarrhea. Retinal toxicity is a known, albeit rare, complication of longterm use, and this effect has been extensively studied, allowing for formal recommendations from the American Academy of Ophthalmology on screening techniques and dosing ${ }^{11,12}$.

In contrast, cardiomyopathy remains widely underreported and without clear recommendations for screening methods or intervals. Antimalarial-induced cardiomyopathy may manifest as hypertrophic or restrictive cardiomyopathy or conduction disturbances like bundle-branch block or atrioventricular block ${ }^{13}$. Because such changes may also be seen in cardiomyopathy due to SLE, differentiating antimalarial-induced cardiomyopathy from that due to SLE may prove difficult. One may begin with an electrocardiogram (ECG) for analysis of cardiac conduction, ischemic change, and left ventricular function, but these findings are

See Cardiomyopathy in SLE, page 391

Personal non-commercial use only. The Journal of Rheumatology Copyright @ 2019. All rights reserved. 
not diagnostic because SLE and antimalarials may both be associated with various nonspecific ECG changes. Echocardiography may help to identify SLE-related structural and functional abnormalities, but again similar findings may be noted with antimalarials, leading us to use cardiac magnetic resonance imaging (cMRI). T2 changes noted on cMRI identify myocardial relaxation abnormalities in SLE even in the preclinical stage ${ }^{14}$. Tselios and colleagues confirmed septal hypertrophy from echocardiography on subsequent cMRI testing but also identified late gadolinium enhancement in 4 patients $^{6 \mathrm{a}}$. However, the significance of the latter findings remains unclear because it pertains to myocardial fibrosis without differentiating the underlying cause. As has been noted, T1 mapping may help to overcome this weakness but more studies evaluating this are necessary.

While consensus on imaging modalities is lacking when faced with diagnosing SLE or antimalarial-induced cardiomyopathy, endomyocardial biopsy remains the gold standard, with recommendations to obtain at least 5 right ventricular samples ${ }^{15}$. The histological findings of antimalarial-induced cardiotoxicity are classically noted to be myofiber necrosis, and autophagic vacuoles are seen ultrastructurally as lamellar inclusion bodies ("myeloid bodies") and "curvilinear bodies" in the cytoplasm ${ }^{10,16,17}$. However, such vacuoles may also be seen in acid maltase deficiency, inclusion body myositis, and some muscular dystrophies, and while these conditions were not suspected in the 8 reported cases here, other diagnostic possibilities must also be taken into consideration. Additionally, while curvilinear bodies are very specific for antimalarial toxicity, lamellar inclusion bodies may also be seen in lysosomal storage diseases and amiodarone use ${ }^{13}$. Cardiomyopathy due to SLE generally yields a nonspecific biopsy with myocyte injury and perivascular and interstitial infiltrate of mononuclear cells with occasional progression to focal muscle fiber necrosis and atrophy ${ }^{15}$. The histological differences here may have clinical and biological significance regarding primary causation (inflammation vs degeneration).

Risks associated with antimalarial-induced cardiotoxicity include older age, female sex, greater duration of therapy, high daily dose, preexisting cardiac disease, and renal dysfunction ${ }^{18,19}$. This study clearly makes an important clinical contribution by reiterating these risks and discussing cardiomyopathy in patients receiving greater cumulative doses of HCQ and chloroquine in their cohort when compared to prior case reports ( $2419 \mathrm{~g}$ vs $1542 \mathrm{~g}$ and $2055 \mathrm{~g}$ vs $1005 \mathrm{~g}$, respectively). However, more information is needed, and greater research required, to establish concrete recommendations for case ascertainment and diagnosis of antimalarial-induced cardiomyopathy. In an era when the majority of patients with SLE are receiving antimalarial therapy, establishing a means to distinguish cardiomyopathy due to SLE itself from antimalarial-induced cardiomyopathy is of utmost relevance and importance. If one is taking HCQ or chloroquine chronically, how long is too long? Who is truly at the highest risk? Is checking drug levels going to help? Prospective studies are necessary to answer these questions and ultimately establish a clinically useful risk assessment tool to prevent cardiotoxicity in patients receiving antimalarial therapy for rheumatic diseases.

\author{
VANEET KAUR SANDHU, MD, \\ Assistant Professor of Medicine, \\ Associate Program Director, \\ Division of Rheumatology, \\ Department of Medicine, \\ Loma Linda University, \\ Loma Linda, California; \\ MICHAEL H. WEISMAN, MD, \\ Emeritus Professor of Medicine, \\ Cedars Sinai Medical Center, \\ Distinguished Professor of Medicine Emeritus, \\ David Geffen School of Medicine \\ at the University of California at Los Angeles, \\ Los Angeles, California, USA.
}

Address correspondence to Dr. V.K. Sandhu, Loma Linda University Medical Center, Rheumatology, 11375 Campus St., Loma Linda,

California 92354, USA. E-mail: vksandhu@1lu.edu

\section{REFERENCES}

1. Jaramillo-Arango JA. Critical review of the basic facts in the history of cinchona. Bot J Linn Soc 1949;53:272-311.

2. Delepine M. Joseph Pelletier and Joseph Caventou. Chem Educ 1951;28:45.

3. Office of the Surgeon General: Circular letter No. 153: The drug treatment of malaria, suppressive and clinical. JAMA 1943;123:205-8.

4. Goodman LS, Gilman A. The pharmacological basis of therapeutics (ed. 2). New York: Macmillan; 1954:1167-73.

5. Page F. Treatment of lupus erythematosus with mepacrine. Lancet 1951;2:755-8.

6. World Health Organization. WHO model list of essential medicines October 2013. [Internet. Accessed June 7, 2018.] Available from: http://apps.who.int/iris/bitstream/handle/10665/93142/EML_18_ eng.pdf;jsessionid=C6E598608CC2DA870A2801231E135D7C? sequence $=1$

6a. Tselios K, Deeb M, Gladman DD, Harvey P, Akhtari S, Mak S, et al. Antimalarial-induced cardiomyopathy in systemic lupus erythematosus: as rare as considered? J Rheumatol 2019;46:391-6.

7. Tselios K, Deeb M, Gladman DD, Harvey P, Urowitz MB. Antimalarial-induced cardiomyopathy: a systematic review of the literature. Lupus 2018;27:591-9.

8. Ritschel WA, Kearns GL. Handbook of basic pharmacokinetics... including clinical applications. 7th ed. Washington, DC: American Pharmacists Association; 2009.

9. Lafyatis R, York M, Marshak-Rothstein A. Antimalarial agents: closing the gate on Toll-like receptors? Arthritis Rheum 2006;54:3068-70

10. Kuncl RW, Wiggins WW. Toxic myopathies. Neurol Clin 1988;6:593-61.

11. Michaelides M, Stover NB, Francis PJ, Weleber RG. Retinal toxicity associated with hydroxychloroquine and chloroquine: risk factors, screening, and progression despite cessation of therapy. Arch Ophthalmol 2011;129:30-9.

12. Marmor MF, Kellner U, Lai TY, Melles RB, Mieler WF; American Academy of Ophthalmology. Recommendations on screening for chloroquine and hydroxychloroquine retinopathy (2016 revision). Ophthalmology 2016;123:1386-94.

Personal non-commercial use only. The Journal of Rheumatology Copyright $\subset$ 2019. All rights reserved. 
13. Tegnér R, Tomé FM, Godeau P, Lhermitte F, Fardeau M. Morphological study of peripheral nerve changes induced by chloroquine treatment. Acta Neuropathol 1988;75:253-60.

14. Singh JA, Woodard PK, Dávila-Román VG, Waggoner AD, Gutierrez FR, Zheng J, et al. Cardiac magnetic resonance imaging abnormalities in systemic lupus erythematosus: a preliminary report. Lupus 2005;14:137-44.

15. Fairfax MJ, Osborn TG, Williams GA, Tsai CC, Moore TL. Endomyocardial biopsy in patients with systemic lupus erythematosus. J Rheumatol 1988;15:593-6.

16. Gérard JM, Stoupel N, Collier A, Flament-Durand J. Morphologic study of a neuromyopathy caused by prolonged chloroquine treatment. Eur Neurol 1973;9:363-79.
17. Rewcastle NB, Humphrey JG. Vacuolar myopathy: clinical, histochemical, and microscopic study. Arch Neurol 1965;12:570-82.

18. Baguet JP, Tremel F, Fabre M. Chloroquine cardiomyopathy with conduction disorders. Heart 1999;81:221-3.

19. Nord JE, Shah PK, Rinaldi RZ, Weisman MH. Hydroxychloroquine cardiotoxicity in systemic lupus erythematosus: a report of 2 cases and review of the literature. Semin Arthritis Rheum 2004; $33: 336-51$

J Rheumatol 2019;46:340-2; doi:10.3899/jrheum.180639 